\title{
SEXUALLY TRANSMITTED DISEASES AMONG MSMS- A RETROSPECTIVE STUDY IN A TERTIARY CARE HOSPITAL FOR A PERIOD OF 18 MONTHS
}

\author{
Chenna Subhashini ${ }^{1}$, Kethireddi S. Divya ${ }^{2}$, Jahnavi Sambangi ${ }^{3}$ \\ ${ }^{1}$ Assistant Professor, Department of DVL, AMC. \\ ${ }^{2}$ Assistant Professor, Department of DVL, GVPIHC and MT. \\ ${ }^{3}$ Postgraduate Student, Department of DVL, AMC.
}

\section{ABSTRACT}

\section{BACKGROUND}

Men who have sex with men (MSMs) are a vulnerable population for spread of Sexually Transmitted Diseases (STDs) and Human Immunodeficiency Virus (HIV). Apart from being important for HIV transmission, they tend to have different distribution patterns of STDs. Few Indian studies have looked into this aspect.

Objective- We retrospectively analysed the available data on MSM from a tertiary care hospital from Jan 2015 to June 2016.

\section{MATERIALS AND METHODS}

We retrospectively analysed the available data on MSM visiting STD op, KGH, Vizag. The pattern of STDs was evaluated in each patient.

\section{RESULTS}

Syphilis was the most common STD followed by urethral discharge and herpes genitalis.

\section{CONCLUSION}

Identification of MSMs is important as most of them are bisexual and promiscuous, thereby playing a role in spread of STDs in vast number of partners. The profile of STDs also differs in MSM, which makes it all the more important to identify them.

\section{KEYWORDS}

Men Sex with Men (MSM), Syphilis, Herpes Genitalis, Condyloma Acuminata, Chancroid, Donovanosis, Candidal Balanoposthitis.

HOW TO CITE THIS ARTICLE: Subhashini C, Divya KS, Sambangi J. Sexually transmitted diseases among MSM's- a retrospective study in a tertiary care hospital for a period of 18 months. J. Evolution Med. Dent. Sci. 2017;6(24):1981-1984, DOI: $10.14260 /$ Jemds/2017/434

\section{BACKGROUND}

MSM is a nomenclature coined in the mid 1980's in an attempt to find an umbrella term to describe a variety of men who have sex with other men, thereby may transmit or acquire HIV or other STD's, but do not necessarily share the same sexual orientation, sexual identity or gender identity.

Male homosexual behaviour has been denounced in the Old Testament and extolled by classical Greek posts like Hesiod, underscoring the longstanding awareness that these behaviours have been commonly expressed since the beginning of human civilisation and demonstrating the ways that diverse cultures have grappled with deviations from the heterosexual norm. ${ }^{1}$ In some communities in India, male homosexual behaviour may be seen as a play, a way of dealing with sexual "needs" or maintaining the social norms that restrict sex with women for purposes other than procreation..$^{2}$ Homosexuality is rarely discussed publically, as it is considered a taboo subject by both Indian Civil Society and the Government.

Financial or Other, Competing Interest: None.

Submission 16-02-2017, Peer Review 11-03-2017,

Acceptance 18-03-2017, Published 23-03-2017.

Corresponding Author:

Kethireddi S. Divya,

7-5-118/3, Flat No.102,

Annika Residency,

Pandurangapuram,

Visakhapatnam-530003.

E-mail: drksdivya89@gmail.com

DOI: $10.14260 /$ jemds $/ 2017 / 434$

\section{(c) $(1)$}

An interesting classification was given by Humsafar trust working for this community, where MSM are classified into different categories based on identity, gender, behaviour and profession. Based on identity they are categorised as "gay," "bisexuals," "Kothis" (receptive partner) or "Panthis" (insertive partners). Transgender are those who are born males, but believe themselves to be females, also referred as "Hijras" or third gender in South Asia. There are MSM who do not identify with queer labels, but are homosexual or bisexual behaviourally. Lastly, there are men who indulge in sex with men for cash or kind. Male Sex Workers (MSWs) encompass all these four broad areas.

The prevalence of male homosexual behaviour in modern, industrialised societies has been estimated as ranging from $1 \%$ to $10 \%$, depending on the sampling interval, lifetime experience vs recent contact and the behaviours that are considered.3,4 Estimates of recent sexual behaviours of adults suggest that $3 \%-7 \%$ of men had a homosexual behaviour in the past year. $5,6,7$

The reasons for risk-taking behaviour are complex. In many cases, concomitant psychosocial health concerns such as depression may predispose MSM to increased STD risk taking. Frequently, these behaviours are in response to societal and familial intolerance of homosexuality. Although, HIV and STD prevalence is high among MSM of all age strata compared with age-matched cohorts in the general population, younger MSM, particularly those who do not discuss their sexual orientation with their partners, friends or health care providers, are at increased risk for HIV and other STDs. Miscommunication and misperceptions about HIV 
serostatus and the presence of STDs may enable some MSM to feel comfortable engaging in unprotected sex.

MSM's are at high risk for HIV infection and other viral, bacterial STD's because MSM may practice anal sex and the rectal mucosa is uniquely susceptible to certain STD pathogens (in addition to multiple sex partners, substance use and sexual network dynamics of MSM further increase the risk). MSM remain at disproportionate risk for HIV acquisition and transmission. Factors that increase the risk for HIV infection in MSM include either receptive anal sex with anonymous partners without a condom and using methamphetamines or drugs that enhance sexual performance. ${ }^{8}$ Increases in unsafe sex have also been associated with an increase in rectal gonorrhoea among MSM. MSM diagnosed with rectal gonorrhoea are more likely to be HIV-infected, use recreational drugs and have partners whose serostatus is unknown to themselves and their partners.

HPV infection and HPV associated conditions are highly prevalent among MSM. The quadrivalent vaccine is recommended routinely for MSM.9,10,11

MSM are at increased risk for acquisition and transmission of hepatitis A and hepatitis B, yet many MSM who are $>21$ years of age remain unvaccinated. Vaccination counselling is extremely important to achieve increased rates of vaccine utilisation by MSM. Although MSM may acquire hepatitis $C$ through sexual means, particularly if traumatic sex is involved (eg, manual insertion, group sex), the prevalence of this infection among individuals who do not share needles or who have other parenteral exposures, remains relatively low $(<5 \%)$, though higher than among the general population.

Interestingly in most of the cases it is bisexual behaviour, which is commoner than isolated homosexual behaviour. ${ }^{12}$ This bisexual behaviour makes MSM a bridge population for spread of Sexually Transmitted Diseases (STD's) and HIV. ${ }^{13}$

Because of the high prevalence of frequently asymptomatic STDs among some MSM, proactive screening by health care providers can play an important role in the early diagnosis and interruption of disease transmission. Some MSM may avoid seeking healthcare, because they expect disapproval regarding their lifestyle, so it is particularly important for clinicians to become culturally competent to provide care for this population by familiarising themselves with existing resource. Optimal care for MSM should include the ability to ask behavioural screening questions in a professional manner without implicit assumptions. Initiating the conversation without judgments can often be helpful. For example, by asking "Do you have sex with men, women or both?" a new patient may feel comfortable in disclosing previously unreported homosexual behaviour. By creating an atmosphere in which MSM feel that they can discuss specific sexual practices and patterns of behaviour, health care professionals can play an instrumental role in arresting the spread of HIV and STDs in this population.

\section{MATERIALS AND METHODS}

We retrospectively analysed the available data on MSM, which included the direct walking to STD OP, KGH, VIZAG and those referred from NGD-YRG care and SEED from Jan 2015 to June 2016. The male patients were identified as MSM's either if they have self-reported to have homosexual or bisexual behaviour or it was elicited after careful history taking.

The diagnosis of various types of STD's was made clinically, substantiated by investigations. HIV screening and venereal diseases research laboratory tests were carried out in all the patients. Additional investigations such as Tzanck smear, gram staining and $\mathrm{KOH}$ smears were carried out whenever required.

All the patients were treated in accordance with the NACO guidelines.

\section{RESULTS}

A total of 387 MSM visited our STD Op from Jan 2015 to June 2016. Syphilis was the most common STD present in $5.16 \%$ of MSM. Out of total 20 patients with syphilis 3 had primary syphilis, 4 had secondary syphilis and 13 had latent syphilis during routine VDRL screening.

$2.32 \%$ of patients presented with urethral discharge. Out of total 9 MSM with urethral discharge, 5 were identified to have gonococcal urethritis and 4 were having nongonococcal urethritis.

$2.06 \%$ (8 out of 387) presented with herpes genitalis, of which three patients had first episode of herpes genitalis and 5 recurrent herpes genitalis.

$1.03 \%$ (4 out of 387) presented with condyloma acuminata, out of them 3 presented with penile warts and one had both penile and perianal warts. The patient with perianal warts gave a history of being passive partner.

3 patients were diagnosed as having chancroid and 1 patient presented with donovanosis; 5 patients presented with candidal balanoposthitis and three presented with genital scabies.

HIV positivity was present in 35 cases (9.04\%). Out of them, 13 patients had VDRL positivity with titres ranging from $1: 8$ to $1: 64$.

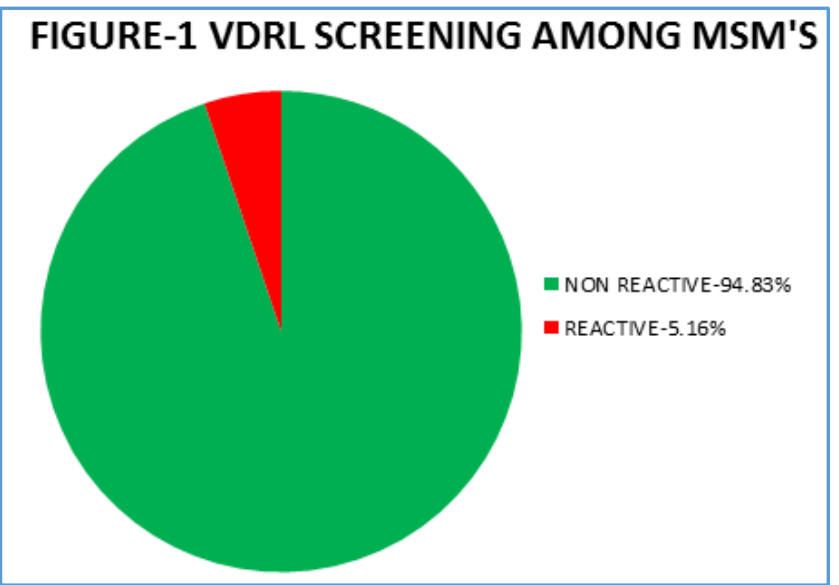




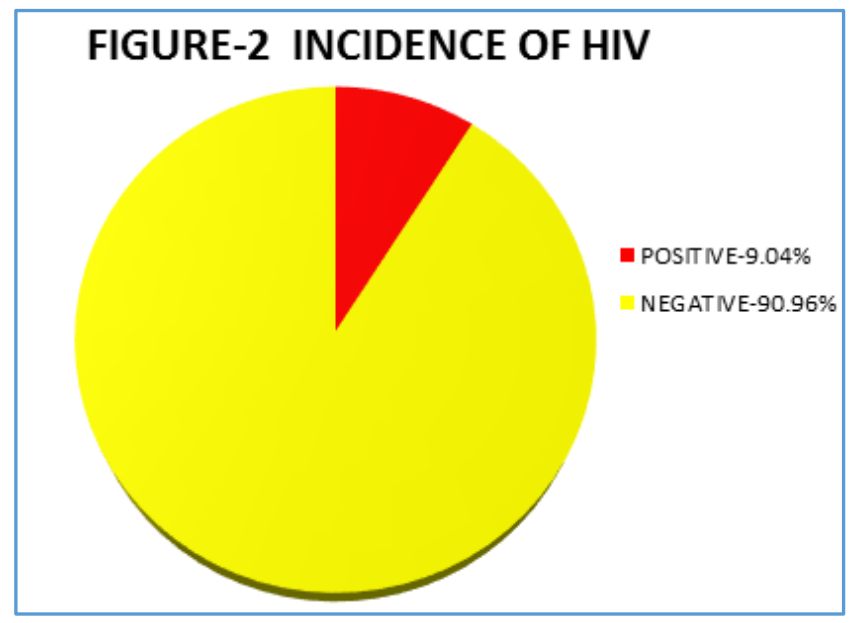

\section{DISCUSSION}

The most common STD recorded in our study was syphilis $(5.16 \%)$ followed by urethral discharge $(2.32 \%)$ and herpes genitalis $(2.06 \%)$. Condyloma acuminata was the next common STD (1.03\%). Small proportions were constituted by chancroid, donovanosis, candidal balanoposthitis and genital scabies.

Studies from India carried out in clinics catering only MSM have shown nearly 20\% of MSM to be affected by some STD's with syphilis, herpes and condyloma acuminata as the most common STDs affecting them.14,15,16 Brahmam et al ${ }^{15}$ also reported a high prevalence of syphilis among "kothis" and "hijras" (15.8\% and $13.6 \%$ respectively), but a low prevalence of gonorrhoea (1\%) and chlamydia (0.4 - 4\%). Another Indian study conducted at Suraksha Clinic of a tertiary hospital in New Delhi by (Garg T et al ${ }^{17}$ recorded syphilis $(27 \%)$ followed by condyloma acuminate $(21 \%)$ and herpes genitalis (19\%), gonococcal infection (11\%) was the fourth most common STD. In our study the incidence was comparatively low, because we included asymptomatic MSM from NGO for screening.

The results in Western studies have been slightly different. In a study on MSM attending three primary health clinics in Boston, gonorrhoea was diagnosed in $25 \%$ and syphilis seropositivity was found in $6.2 \% .18$

HIV seropositivity was found in 35 cases (9.04\%) out of total 387 MSMs in our study. The current estimated HIV prevalence among MSM in India is ranging between 7 and 16.5 percent. $19,20,21$

\section{CONCLUSION}

Large numbers of studies on STD profile of MSM are present from the Western world. However, these cannot be applied for Indian population because of the difference in social and cultural behaviour. Henceforth, we carried out this to delineate the clinical patterns of STD's in MSM coming to our OPD. This study highlights the profile of STDs among male homosexuals attending King George Hospital (a tertiary care hospital).

\section{REFERENCES}

[1] Karlen A. Sexuality and homosexuality: a new view. New York: WW Norton and Company Inc.,1971:1-647.

[2] Asthana S, Oostvogels R. The social construction of male 'homosexuality' in India: implications for HIV transmission and prevention. Soc Sci Med 2001;52(5): 707-21.
[3] Fay RE, Turner CF, Klassen AD, et al. Prevalence and patterns of same-gender sexual contact among men. Science 1989;243(4889):338-48.

[4] Rogers SM, Turner CF. Male-male sexual contact in the USA: findings from five sample surveys, 1970-1990. J Sex Res 1991;28(4):491-519.

[5] Stall RD, Hays RB, Waldo CR, et al. The Gay '90s: a review of research in the 1990s on sexual behavior and HIV risk among men who have sex with men. AIDS 2000;14(Suppl 3): S101-S14.

[6] Binson D, Michaels S, Stall R, et al. Prevalence and social distribution of men who have sex with men: United States and its urban centers. J Sex Res 1995;32(3):245-54.

[7] Turner CF, Ku L, Rogers SM, et al. Adolescent sexual behavior, drug use and violence: increased reporting with computer survey technology. Science 1998;280(5365):867-73.

[8] Ackers ML, Greenberg AE, Lin CY, et al. High and persistent HIV seroincidence in men who have sex with men across 47 U.S cities. PLoS One 2012;7(4):e34972.

[9] Markowitz LE, Dunne EF, Saraiya M, et al. Human papillomavirus vaccination: recommendations of the Advisory Committee on Immunization Practices (ACIP). MMWR Recomm Rep 2014;63(No. RR-05):130.

[10] CDC. Recommendations on the use of quadrivalent human papillomavirus vaccine in males: Advisory Committee on Immunization Practices (ACIP). MMWR Morb Mortal Wkly Rep 2011;60(50):1705-8.

[11] Palefsky JM, Giuliano AR, Goldstone S, et al. HPV vaccine against anal HPV infection and anal intraepithelial neoplasia. $\mathrm{N}$ Engl J Med 2011;365(17):1576-85.

[12] Indian Council of Medical Research. HIV infection: current dimensions and future implications. ICMR Bull 1992;22:113-26.

[13] Verma RK, Collumbien M. Homosexual activity among rural Indian men: Implication for HIV intervention. AIDS 2004;18(13):1845-7.

[14] Shinde S, Setia MS, Row-Kavi A, et al. Male sex workers: Are we ignoring a risk group in Mumbai, India? Indian J Dermatol Venereol Leprol 2009;75(1):41-6.

[15] Brahmam GN, Kodavalla V, Rajkumar H, et al. Sexual practices, HIV and sexually transmitted infections among self-identified men who have sex with men in four high HIV prevalence states of India. AIDS 2008;22 Suppl 5:S45-57.

[16] Setia MS, Lindan C, Jerajani HR, et al. Men who have sex with men and transgenders in Mumbai, India: an emerging risk group for STIs and HIV. Indian J Dermatol Venereol Leprol 2006;72(6):425-31.

[17] Garg T, Chander R, Jain A, et al. Sexually transmitted diseases among men who have sex with men: a retrospective analysis from Suraksha clinic in a tertiary care hospital. Indian J Sex Transm Dis 2012;33(1):16-9. 
[18] Mimiaga MJ, Helms DJ, Reisner SL, et al. Gonococcal, chlamydia and syphilis infection positivity among MSM attending a large primary care clinic, Boston, 2003 to 2004. Sex Transm Dis 2009;36(8):507-11.

[19] United Nations General Assembly Special Session on HIV/ AIDS, India 2010. New Delhi: National AIDS Control Organization, 2010.
[20] Independent Evaluation of National AIDS Control Programme. Jaipur: Indian Institute of Health Management Research. 2007.

[21] Thomas B, Mimiaga MJ, Menon S, et al. Unseen and unheard: predictors of sexual risk behavior and HIV infection among men who have sex with men in Chennai, India. AIDS Educ Prev 2009;21(4):372-83. 